\title{
Synergistic effects of catalytic co-pyrolysis Chlorella vulgaris and polyethylene mixtures using artificial neuron network: Thermodynamic and empirical kinetic analyses
}

\author{
Tshun Li Yap ${ }^{\text {a }}$, Adrian Chun Minh Loy ${ }^{\text {b,c, d }}$, Bridgid Lai Fui Chin ${ }^{\text {a, * , Juin Yau Lim }}{ }^{\text {, }}$ \\ Hatem Alhamzi ${ }^{\mathrm{f}}$, Yee Ho Chai ${ }^{\mathrm{c}, \mathrm{d}}$, Chung Loong Yiin ${ }^{\mathrm{g}}$, Kin Wai Cheah ${ }^{\mathrm{h}}$, Melvin Xin Jie Wee ${ }^{\mathrm{a}}$, \\ Man Kee Lam ${ }^{\text {c, }}$, Zeinab Abbas Jawad ${ }^{i}$, Suzana Yusup ${ }^{j}$, Serene Sow Mun Lock ${ }^{k}$ \\ ${ }^{a}$ Department of Chemical and Energy Engineering, Faculty of Engineering and Science, Curtin University Malaysia, CDT 250, 98009 Miri Sarawak, Malaysia \\ ${ }^{\mathrm{b}}$ Department of Chemical Engineering, Monash University, Victoria 3800, Australia \\ ${ }^{\mathrm{c}}$ HICoE - Centre for Biofuel and Biochemical Research, Institute of Self-Sustainable Building, Department of Chemical Engineering, Universiti Teknologi PETRONAS, \\ 32610 Seri Iskandar, Perak, Malaysia \\ ${ }^{\mathrm{d}}$ Department of Chemical Engineering, Universiti Teknologi PETRONAS, 32610 Seri Iskandar, Perak, Malaysia \\ e Integrated Engineering, Dept. of Environmental Science and Engineering, College of Engineering, Kyung Hee University, 1732 Deogyeong-daero, Giheung-gu, Yongin-Si, \\ Gyeonggi-do 17104, Republic of Korea \\ ${ }^{\mathrm{f}}$ National Center for Environmental Technology (NCET), King Abdulaziz City for Science and Technology (KACST), P.O. Box 6086, 11442 Riyadh, Saudi Arabia \\ ${ }^{\mathrm{g}}$ Department of Chemical Engineering and Energy Sustainability, Faculty of Engineering, Universiti Malaysia Sarawak (UNIMAS), 94300, Kota Samarahan, Sarawak, \\ Malaysia \\ ${ }^{\mathrm{h}}$ Teesside University, School of Science and Engineering, Borough Road, Middlesbrough TS1 3BA, United Kingdom \\ ${ }^{i}$ Department of Chemical Engineering, College of Engineering, Qatar University, P.O. Box: 2713, Doha, Qatar \\ ${ }^{\mathrm{j}}$ Generation Unit (Fuel Technology \& Combustion), Tenaga Nasional Berhad (TNB) Research Sdn Bhd, No.1, Kawasan Institusi Penyelidikan, Jln Ayer Hitam, 43000 \\ Kajang, Selangor, Malaysia \\ ${ }^{\mathrm{k}}$ CO2 Research Center (CO2 RES), Department of Chemical Engineering, Universiti Teknologi PETRONAS, Seri Iskandar 32610, Malaysia
}

\section{A R T I C L E I N F O}

Editor: Apostolos Giannis

\section{Keywords:}

Catalytic pyrolysis

Kinetic analysis

Empirical modelling

Artificial neural network

Genetic algorithm

Microalgae Chlorella vulgaris

\begin{abstract}
A B S T R A C T
The catalytic pyrolysis of Chlorella vulgaris, high-density polyethylene (Pure HDPE) and, their binary mixtures were conducted to analyse the kinetic and thermodynamic performances from 10 to $100 \mathrm{~K} / \mathrm{min}$. The kinetic parameters were computed by substituting the experimental and ANN predicted data into these iso-conversional equations and plotting linear plots. Among all the iso-conversional models, Flynn-Wall-Ozawa (FWO) model gave the best prediction for kinetic parameters with the lowest deviation error (2.28-12.76\%). The bifunctional HZSM-5/LS catalysts were found out to be the best catalysts among HZSM-5 zeolite, natural limestone (LS), and bifunctional HZSM-5/LS catalyst in co-pyrolysis of binary mixture of Chlorella vulgaris and HDPE, in which the $E_{a}$ of the whole system was reduced from range $144.93-225.84 \mathrm{~kJ} / \mathrm{mol}$ (without catalysts) to $75.37-76.90 \mathrm{~kJ} / \mathrm{mol}$. With the aid of artificial neuron network and genetic algorithm, an empirical model with a mean absolute percentage error (MAPE) of 51.59\% was developed for tri-solid state degradation system. The developed empirical model is comparable to the thermogravimetry analysis (TGA) experimental values alongside the other empirical model proposed in literature
\end{abstract}

\section{Introduction}

Energy plays an irreplaceable role in human's daily lives for centuries and also being regarded as the main principal factor for a country's socio-economic development. According to the International Energy Agency (IEA), the total world's energy from non-renewable fossil

\footnotetext{
* Corresponding author.

E-mail addresses: 700017566@student.curtin.edu.my (T.L. Yap), adrian.loy@monash.edu (A.C.M. Loy), bridgidchin@gmail.com, bridgidchin@curtin.edu.my (B.L.F. Chin), juinyau95@gmail.com (J.Y. Lim), halhazmi@kacst.edu.sa (H. Alhamzi), yeeho.chai@utp.edu.my (Y.H. Chai), clyiin@unimas.my (C.L. Yiin), cheahkinwai@hotmail.com (K.W. Cheah), melvinweexj@postgrad.curtin.edu.my (M.X.J. Wee), lam.mankee@utp.edu.my (M.K. Lam), zjawad@qu.edu.qa (Z.A. Jawad), suzana.yusup@tnb.com.my (S. Yusup), sowmun.lock@utp.edu.my (S.S.M. Lock).
} 